\title{
RETRACTED ARTICLE: Agrobacterium tumefaciens-mediated transformation and efficient regeneration of a timber yielding plant Dalbergia sissoo Roxb.
}

\author{
Chinmay Pradhan - Ajantaa Pal • Anath B. Das • \\ Pradeep K. Chand
}

Published online: 15 February 2013

(C) Prof. H.S. Srivastava Foundation for Science and Society 2013

The manuscript has been withdrawn by the authors after it was pointed out by the editor that it was already published elsewhere. The letter of retraction from the authors states: "Now that the earlier version of our paper has already been printed in the "J. Plant Studies" in its recent issue (Vol. 2, No. 1, 2013), we are writing to the Chief Editor of the
PMBP to withdraw the article (DOI 10.1007/s12298-0130163-9) before it is finally printed in the Journal in order that an undesirable duplication would be avoided and our professional ethics be upheld. On behalf of all the coauthors, I sincerely apologize for the inconvenience caused to you.
The manuscript has been withdrawn by the authors after it was pointed
out by the editor that it was already published elsewhere. The letter of
retraction from the authors states: "Now that the earlier version of our
paper has already been printed in the "J. Plant Studies" in its recent
issue (Vol. 2, No. 1, 2013), we are writing to the Chief Editor of the
PMBP to withdraw the article (DOI 10.1007/s12298-013-0163-9)
before it is finally printed in the Journal in order that an undesirable
duplication would be avoided and our professional ethics be upheld.
On behalf of all the co-authors, I sincerely apologize for the
inconvenience caused to you.

\section{Pradhan $\cdot$ P. K. Chand}

Plant Cell \& Tissue Culture Facility, Post-Graduate Department of

Botany, Utkal University, Bhubaneswar 751 004, Odisha, India

\section{A. Pal • A. B. Das}

Division of Plant Biotechnology, Regional Plant Resource Centre,

Bhubaneswar 751 015, Odisha, India

\section{Present Address:}

A. Pal

Department of Life Sciences, Regional Institute of Education,

Bhubaneswar 751 022, Odisha, India

Present Address:

A. B. Das $(\triangle)$

Department of Agricultural Biotechnology, Orissa University of Agriculture and Technology, Bhubaneswar 751 003, Odisha, India e-mail: a_b_das@hotmail.com 